\title{
АКТУАЛЬНЫЕ ПРОБЛЕМЫ ПРОТИВОДЕЙСТВИЯ ОТМЫВАНИЮ ДЕНЕЖНЫХ СРЕДСТВ В БАНКОВСКОЙ СФЕРЕ И ПУТИ ИХ РЕШЕНИЯ
}

\author{
(c) 2020 Константинов Илья Алексеевич
}

студент второго курса магистратуры по направлению: «Юрист в сфере финансовых рынков» Санкт-Петербургский государственный университет, Россия, Санкт-Петербург

E-mail: ilyakonstant1nov@yandex.ru

В статье произведен анализ действующего законодательства и сложившейся правоприменительной практики в части противодействия отмыванию преступных доходов в банковской сфере Российской Федерации. На основе проведенного научного исследования были предложены варианты решения имеющихся проблем.

Ключевые слова: Федеральный закон от 07.08.2001 N 115-ФЗ, отмывание преступных доходов, Центральный Банк, правила внутреннего контроля, финансовый мониторинг, сомнительные операции, ФАТФ, банки.

Впервые термин «отмывание денег» был использован в США в г. Чикаго в 20-х годах 20-го века во время так называемого «Сухого закона». Применительно к тому периоду вышеназванный термин обозначал ввод в законный оборот денежных средств, полученных от незаконной продажи алкоголя (по ночам преступники засыпали в автоматы для стирки вещей монеты, вырученные от незаконной продажи алкоголя, а на следующий день инкассировали их в банки под видом выручки от оказания соответствующих законных услуг прачечных) [1].

В современном смысле (в юридическом и экономическом смысле) такой термин, как отмывание денежных средств («money laundering») впервые был использован в США в 80-е годы для целей определения процесса преобразования нелегально полученных денежных средств в законный источник дохода применительно к наркобизнесу. Так, президентская комиссия США, созданная при администрации Рональда Рейгана, которая занималась противодействием организованной преступности, использовала следующую формулировку: «Отмывание денег процесс, посредством которого скрывается существование, незаконное происхождение или незаконное использование доходов и затем эти доходы маскируются таким образом, чтобы казаться имеющими законное происхождение» [2].

Говоря предметно о российском законодательстве, понятия «доходов, полученных преступным путем» и «легализации (отмывания) доходов, полученных преступным путем» закреплены в статье 2 Федерального закона от
07.08.2001 N 115-ФЗ (ред. от 01.03.2020) «О противодействии легализации (отмыванию) доходов, полученных преступным путем, и финансированию терроризма». Так, согласно вышеназванному ФЗ, доходы, полученные преступным путем,- денежные средства или иное имущество, полученные в результате совершения преступления, а легализация (отмывание) доходов, полученных преступным путем,- придание правомерного вида владению, пользованию или распоряжению денежными средствами или иным имуществом, полученными в результате совершения преступления. Исходя из вышеназванных определений можно выявить существенные признаки такого понятия, как «легализация (отмывание) доходов, полученных преступным путем»:

1. Предмет - доходы (денежные средства или иное имущество).

2. Источник происхождения доходов - peзультат совершения уголовного преступления.

3. Сокрытие незаконного источника происхождения доходов от преступной деятельности (придание правомерного вида владению, пользованию или распоряжению доходам, полученным преступным путем).

Актуальность проводимого исследования обусловлена целым рядом правовых, экономических и социальных проблем и вызовов, которые стоят на сегодняшний день перед Российской Федерацией. Легализация(отмывание) денежных средств, добытых преступным путем приводит к развитию преступного бизнеса(что серьезным образом подрывает социально- 
правовую структуру общества), нарушает законные социально-экономические связи, подрывает условия здоровой конкуренции между хозяйствующими субъектами путем притока в легальные сферы экономической деятельности значительных сумм денежных средств, добытых преступным путем и к целому ряду других крайне неблагоприятных последствий для всего государства и общества в целом.

Для наглядной иллюстрации тех проблем, которые возникают вследствие легализация денежных средств, добытых преступным путем (или напрямую коррелируют с данным явлением) обратимся к официальной статистике публичных органов власти.

Росфинмониторингом был предоставлен публичный отчет, касающийся национальной оценки рисков легализации(отмывания) преступных доходов за 2017-2018 г.(более свежие данные не были предоставлены данным государственным органом), в котором им были указаны на наиболее уязвимые области, которые в наибольшей степени подвержены отмыванию денежных средств, добытых преступным путем. По результатам проведенного анализа были установлены следующие предметные сферы риска [3]:

1. Кредитно-финансовая сфера

2. Сфера бюджетных отношений (включая налоговую сферу)

3. Область коррупционных правонарушений

4. Сфера незаконного оборота наркотиков

Оценивая представленные наиболее уязвимые области, можно прийти к выводу о том, что ими охватываются крайне значимые сферы экономической жизни общества (особенно кредитно-финансовая сфера и сфера бюджетных отношений). При этом, на данный момент большинство экспертов сходятся во мнении, что основным каналом легализации денежных средств, добытых преступным путем, является именно банковская сфера ввиду крайне разнообразного инструментария в кредитно-финансовой сфере.

Масштабы участия банков в отмывании денежных средств, добытых преступным путем, хотя бы отчасти могут проиллюстрировать примеры отзыва лицензий у коммерческих банков Банком России по причине вовлеченности коммерческих банков в сомнительные финансовые операции (примерами могут служить: «Владимирский промышленный банк», московский
«Межтопэнергобанк», омский «Сибэс» и т.д.) [4].

Понятие «сомнительная операция» является краеугольным в Российской правовой системе в части противодействия отмыванию преступных доходов, однако оно не закреплено ни в одном существующем нормативно-правовом акте в законодательстве Российской Федерации ни на уровне закона, ни на уровне подзаконного акта. Так же, судебной практикой не выработано общее определение понятия «сомнительная операция», несмотря на то, что в своих решениях суды часто апеллируют вышеназванным термином. Перечень возможных признаков сомнительных операций назван в письме Банка России от 31.12.2014 N 236-Т(зачисление денежных средств на счет клиента от большого количества других резидентов со счетов, открытых в банках Российской Федерации, с последующим их списанием; списание денежных средств со счета производится в срок, не превышающий двух дней со дня их зачисления; проводятся регулярно (как правило, ежедневно); проводятся в течение длительного периода времени (как правило, не менее трех месяцев); деятельность клиента, в рамках которой производятся зачисления денежных средств на счет и списания денежных средств со счета, не создает у его владельца обязательств по уплате налогов либо налоговая нагрузка является минимальной; с используемого для указанных операций счета уплата налогов или других обязательных платежей в бюджетную систему Российской Федерации не осуществляется или осуществляется в незначительных размерах, не сопоставимых с масштабом деятельности владельца счета). Исходя из сложившейся судебной практики и формулировки письма Банка России от 31.12.2014 N 236-Т о том, что транзитные операции могут характеризоваться совокупностью (одновременным наличием) вышеназванных признаков, позволяют сделать вывод о том, что представленный перечень не является исчерпывающим, а содержит в себе лишь наиболее типичные характеристики транзитных операций.

Однако, на мой взгляд, общие существенные признаки сомнительной операции (которые будут характеризовать всю совокупность вышеназванных операций) все-таки можно вывести из письма Банка России от 31.12.2014 N 236-Т. К таким признакам относятся:

- Движение денежных средств между различными банковскими счетами 
- Отсутствие очевидного экономического смысла и очевидной законной цели в проведении вышеназванных операций

Таким образом, исходя из вышеназванного, мы можем сделать вывод о том, что представленные признаки сформулированы крайне широко, что дает большой простор для квалификации тех или иных банковских операций в качестве сомнительных.

В ходе анализа судебной практики по вопросам противодействия транзитным операциям в банковской сфере мною было рассмотрено 15 судебных решений, вступивших в законную силу (по несколько судебных решений в 8 ар- битражных округах) во временном диапазоне 2016-2020 годов. Во всех рассмотренных мною делах истцами были либо ООО, либо ИП. Стоит отметить, в 12 судебных разбирательствах истцами выступали представители OOO, и в 3 судебных разбирательствах истцами выступали представители ИП. При этом, в 2 из 3 судебных заседаниях исковые требования представителей ИП в части признания незаконной квалификации банками их операций в качестве транзитных и снятия ограничений с банковского счета были удовлетворены и лишь в 2 судебных актах из 12 аналогичные исковые требования представителя ООО были удовлетворены.
14

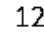

10

8

6

4

2

0

\section{Истцы}

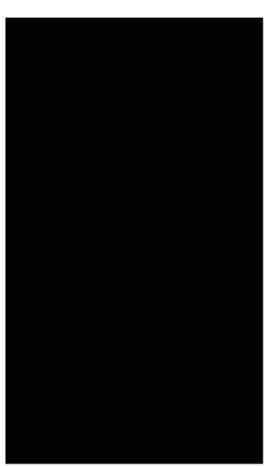
Представители 000

12

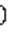

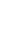

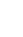

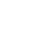
.

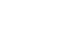


Данная статистика свидетельствует о том, что на данный момент в сомнительных операциях крупный бизнес (акционерные общества), государственные и муниципальные предприятия практически не вовлечены(в ходе анализа судебной практики вышеназванные структуры являлись лишь контрагентами в ряде сделок. При этом, ни в одном судебном решении вышеназванные структуры не были включены ни в один из банковских «стоп-листов»). Помимо этого, основной массив транзитных операций совершался именно ОOО, а не ИП, что объясняется относительной простотой создания ООО, ограниченностью ответственности учредителей, возможностью создания большого количества ООО с их последующим корпоративным контролем для целей маскировки сомнительных операций и сокрытия конечных бенефициаров за номинальными учредителями и директорами. Данный вывод подтверждается в публичном отчете Росфинмо- ниторинга, посвященном национальной оценке рисков легализации преступных доходов. Вышеназванный отчет указывает на то, что использование номинальных юридических лиц-резидентов в схемах отмывания доходов, полученных преступным путем относится к группе высокого риска в рамках национальной оценки угроз рисков легализации преступных доходов [3].

Анализируя ответчиков, был сделан вывод о том, что практически в половине случаев ответчиком выступал ПАО «Сбербанк» (в 7 случаях из 15), в 2 судебных разбирательствах ответчиком выступал ПАО «Промсвязьбанк», и по одному разу ответчиками выступали АО КБ «ЛОКО-БАНК», АО КБ «Райффайзенбанк», ПАО КБ «Тимер Банк», Банк «Открытие» и «Россесельхозбанк». Анализируя количество удовлетворенных исковых заявлений, было обнаружено, что у ПАО «Сбербанк», ПАО КБ «Тимер Банк» и у Банка «Открытие» имеется по одному проигранному делу.

\section{Количество судебных разбирательств у ответчиков}

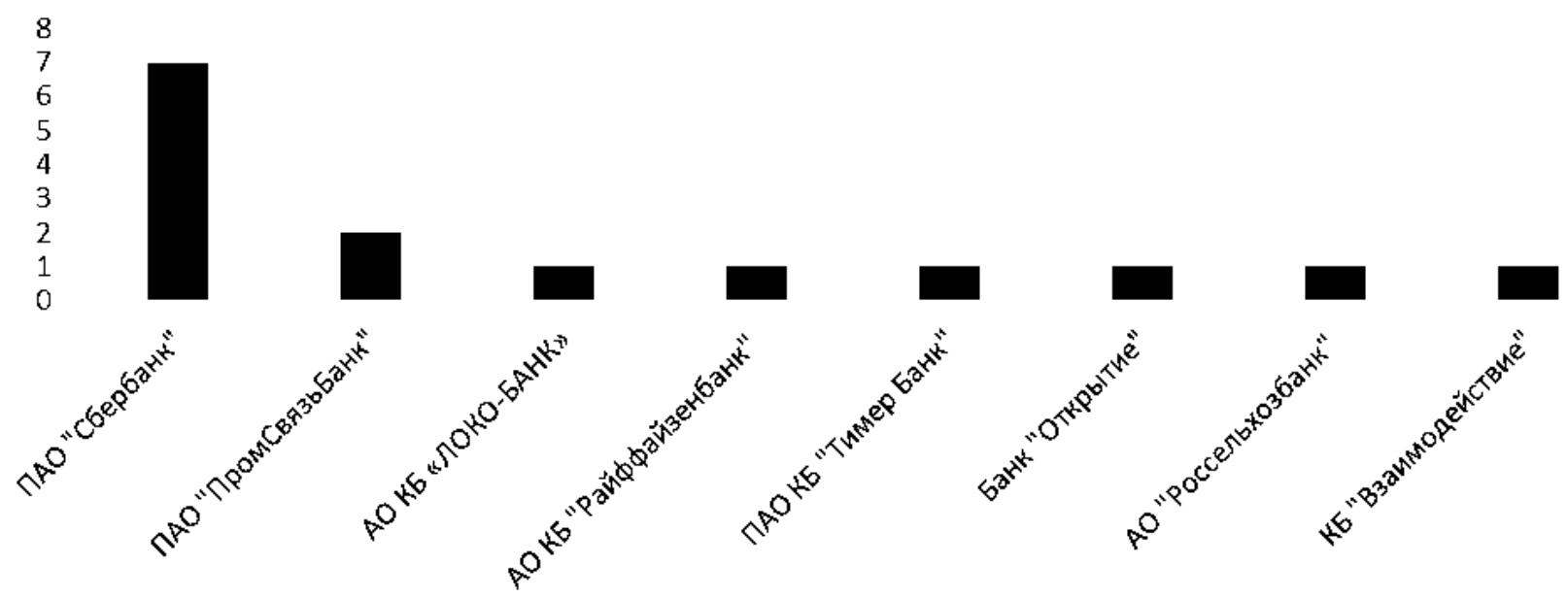

\section{Судебные разбирательства с ПАО "Сбербанк"}

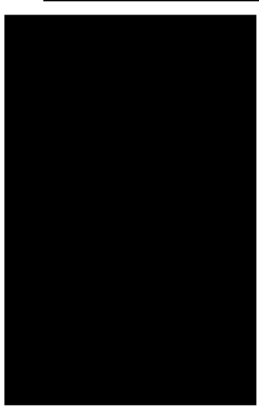

Сүдеьные решения в пользу ПАО "Сбербанк"

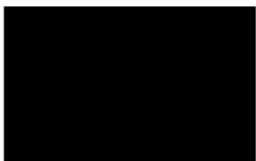

Сүдебные решения в пользу процессуального оппонента ПАО "Сбербанк" 
Исходя из анализа представленных данных, можно прийти к выводу о том, что в большинстве случаев ответчиками выступали крупные банки(при этом, в 7 случаях из 15 ответчиком выступал ПАО «Сбербанк»). Ввиду того, что практически все остальные банки, которые представлены в статистике, выступали в роли ответчиков по одному разу (кроме ПАО «Промсвязьбанк», который был ответчиком 2 раза. Однако, данного количества так же недостаточно для суждения об эффективности работы по противодействию транзитным операциям), нельзя сделать вывод об эффективности работы по противодействию транзитным операциям в иных банках, кроме ПАО «Сбербанк». Исходя из того, что в 5 случаях из 7 ПАО «Сбербанк» правомерно квалифицировал операции клиентов как транзитные и наложил ограничения на банковский счет, можно сделать вывод о том, что сотрудники ПАО «Сбербанк» обладают надлежащей квалификацией в рамках полномочий, предоставленных банкам Ф3 «О противодействии легализации денежных средств, добытых преступным путем».

При анализе представленной судебной практики, в 3 судебных решениях из 15 оценивалось правомерность введения специального заградительного тарифа при совершении сомнительных операций.

Во всех трех рассмотренных случаях суды всех инстанций признали правомерным введение банками специальных заградительных тарифов. Единственный суд, который признал неправомерным введение специального заградительного тарифа Арбитражный суд Новосибирской области. Все остальные суды признали законным введение специального штрафного тарифа.
Помимо этого, стоит так же указать на противоречивую практику даже на уровне высших судов по данному вопросу. Так, в ВС РФ указал на то, что банки в силу положения Федерального закона Российской Федерации от 7 августа 2001 г. N 115-Ф3 «О противодействии легализации (отмыванию) доходов, полученных преступным путем, и финансированию терроризма» были вправе взимать спорную комиссию при выявлении обстоятельств, дающих основание отнести сделки клиента к сомнительным, суд апелляционной инстанции не учел, что в данном федеральном законе не содержатся нормы, позволяющие кредитным организациям в качестве мер противодействия легализации доходов, полученных преступным путем, устанавливать специальное комиссионное вознаграждение. При этом, несмотря на то, что в данном обзоре рассматривалось дело, где в качестве истца выступало физическое лицо, не занимавшееся предпринимательской деятельностью, исходя из буквального толкования, можно прийти к выводу о том, что ВС РФ не подразумевал ограничений из правила о недопустимости введения специальных заградительных комиссий(в т.ч. и по субъектному составу). Помимо этого, подавляющее большинство договоров банковского обслуживания по своей природе являются договорами присоединения по смыслу статьи 428 ГК РФ, и клиенты банков в подавляющем большинстве случаев не имеют возможности повлиять на условия заключения договоров банковского обслуживая, ввиду чего, представляется справедливым распространение правила описанного в Обзоре судебной практики Верховного Суда Российской Федерации N 4 (2019)» (утв. Президиумом Верховного Суда РФ 25.12.2019) о недопустимо-

\section{Введение банком специального заградительного тарифа в случае нарушения клиентом Ф3 "О противодействии отмыванию денежных средств, добытых преступным путем"}

15

10

5

0

Количество дел, в которых банками были введены специальные заградительные тарифы

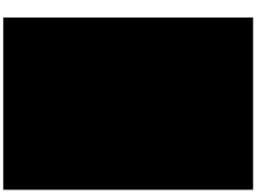

Количество дел, в которых банками не были введены специальные заградительные тарифы 
сти взимания заградительных комиссий на все случаи, когда имеются неравные переговорные возможности вне зависимости от осуществления предпринимательской деятельности одной или всеми сторонами договора банковского обслуживания, и где клиенты банков фактически не имеют возможности повлиять на изменение условий договора. В случае, если самому банку был причинен какой-либо вред в области гражданских правоотношений из-за неправомерных действий клиента в рамках 115-Ф3, то данный вред должен быть возмещен исходя из положений ГК РФ о возмещении убытков.

Сроки, за которые банки приходили к выводу о совершении клиентом транзитных операций крайне варьируются.

Средний срок, за которые банки приходят к выводу о совершении их клиентами транзитных операций составляет 4 месяца (8-е дело не попало в статистику потому что в рамках названного процесса истец лишь требовал взыскать сумму штрафной комиссии за перевод денежных средств. Требования истца не касались снятия ограничений по операциям с банковским счетом).

Анализируя представленную статистику, можно прийти к выводу о том, что банки в относительно короткие сроки (от 1-го до 3-х месяцев) выявляли лишь относительно простые транзитные операции (как например транзитные операции, совершенные ООО «Аз Бенто- нит» в деле № 6. Как было установлено судом, в соответствии с представленным штатным расписанием общая численность работников ООО «Аз Бентонит» - 4 человека (генеральный директор с окладом в 11500 руб., 2 инженераконструктора с окладом в 26440 руб. и конструктор с окладом в 23000 руб.), при этом за период с начала обслуживания по счету операций по выплате заработной платы (в том числе директору и учредителю) по счету в банке (ответчика) ни разу не было осуществлено, а в соответствии с представленными копиями платежных поручений по выплате заработной платы из стороннего банка следует, что ежемесячные выплаты на человека не превышали 20000 руб., тогда как на выплату средств за услуги по управлению бизнес-процессами ежемесячно перечислялись денежные средства в размере в среднем 6000 000 руб. По сведениям Банка, за первый квартал 2016 года клиентом заявлена прибыль в размере 204921 руб., при этом за первый квартал 2016 г., начиная с даты открытия счета, в пользу управляющих директоров переведено более 9000000 руб.). В ситуациях же, когда взаимоотношения контрагентов носили более запутанный и неочевидный характер, где стороны имели расчетные счета в разных банках, период выявления сомнительных операций существенно вырастал (как например в деле № 4 или в деле № 9).

Я полагаю, что данные существенные сроки объясняются отсутствием правового механизма,

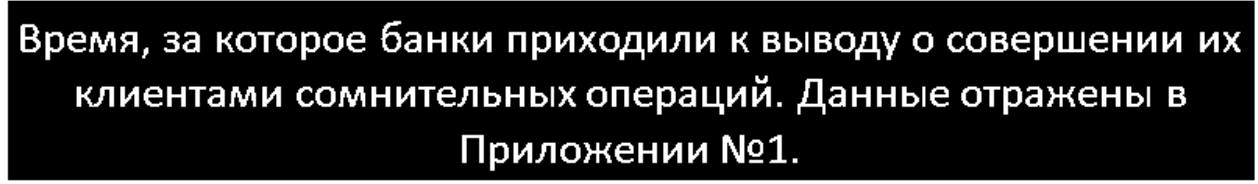

14

12

10

8

6

4

2

0

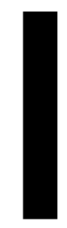

Дело №1

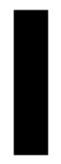

Дело №2
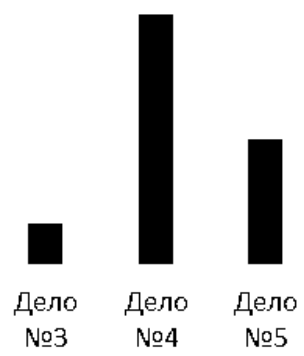

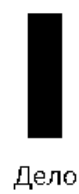

№6

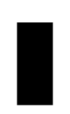

Дело №7

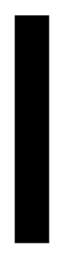

Дело №9

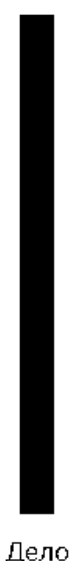

Дело Дело №10 №11
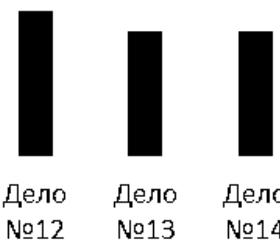

Дело №14

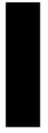

Дело №15 
который бы обеспечивал оперативное взаимодействие субъектов, наделенных полномочиями в рамках пунктов 13.1-13.3 статьи 7115-ФЗ. В рамках вышеназванных норм происходит лишь взаимодействие банков с органами публичной власти (Росфинмониторингом и ЦБ РФ). Данные процедуры являются довольно трудоемкими и требуют много времени для их проведения. В рамках 115-Ф3 необходимо разработать механизм взаимодействия банков между собой для оперативного реагирования на угрозы, которые отражены в ФЗ «О противодействии легализации денежных средств, добытых преступным путем» для максимального нивелирования ущерба финансовой системе от сомнительных операций.

Помимо этого, сложившаяся судебная практика по допущению введения банками заградительных тарифов(которые в своей сути являются неустойками) представляется незаконной и необоснованной ввиду того, что неустойка вве- дена в рамках гражданского законодательства и используется в качестве способа обеспечения исполнения гражданско-правовых обязательств и в качестве меры имущественной ответственности за неисполнение или ненадлежащее исполнение именно обязательств именно в рамках гражданско-правовых отношений, а так же из-за того, что те дополнительные обязанности и те специальные полномочия, которые накладываются на банки в рамках вышеназванного закона имеют под собой публично-правовую природу и направленны на защиту публично-правовых интересов общества и государства.

Практика, описанная выше, имеет еще один негативный аспект. На данный момент, допустимой признается такая практика, при которой клиент банка, который замешан в сомнительных операциях, сможет выводить денежные средства в другие банки, лишь заплатив ту самую заградительную комиссию.

\section{Библиографический список}

1. Лекция: Отмывание денег как экономический феномен современности и организационные основы противодействия противодействия / Магомедов Ш. М., Каратаев М.В.

2. Статья: Институт противодействия легализации преступных доходов в науке и практике современной международной юриспруденции / А. В. Водянов

3. Публичный отчет Росфинмониторинга: национальная система оценки рисков легализации (отмывания) преступных доходов

4. Статья: Актуальные проблемы противодействия легализации преступных доходов в банковской сфере (Лавроненко Р.А.) («Безопасность бизнеса», 2018, N 2) 